DELEITO, C.S.R.; CARMO, M.G.F.; FERNANDES, M.C.A.; ABBOUD, A.C.S. Ação do biofertilizante Agrobio sobre a mancha-bacteriana e desenvolvimento de mudas de pimentão. Horticultura Brasileira, Brasília, v.23, n.1, p.117-122, jan.-mar. 2005.

\title{
Ação do biofertilizante Agrobio sobre a mancha-bacteriana e desenvolvi- mento de mudas de pimentão ${ }^{1}$
}

\author{
Cláudia S.R. Deleito²; Margarida Goréte F. do Carmo²; Maria do Carmo de A. Fernandes ${ }^{3}$; Antonio \\ Carlos de S. Abboud ${ }^{2}$ \\ ${ }^{2}$ UFRRJ, Depto. Fitotecnia; ${ }^{3}$ PESAGRO-RIO, 23851-970 Seropédica-RJ; E-mail: csayaord@ufrrj.br; gorete@ufrrj.br
}

\begin{abstract}
RESUMO
O biofertilizante Agrobio é produzido a partir de esterco bovino fresco, água, melaço e sais minerais em recipientes abertos. Tem sido largamente utilizado por agricultores orgânicos e convencionais no estado do Rio de Janeiro, ao qual atribuem efeito nutricional e de controle de doenças. O presente trabalho foi feito com o objetivo de elucidar e quantificar aspectos relativos ao efeito do Agrobio sobre o controle da mancha-bacteriana e desenvolvimento de mudas de pimentão, em condições de casa-de-vegetação. Utilizaram-se as cultivares Cascadura Ikeda e Cascadura Itaipu e os tratamentos à base de Agrobio, diluído a 5\% em água destilada, previamente submetido aos seguintes preparos: original; autoclavado $\left(120^{\circ} \mathrm{C} / 20 \mathrm{~min}\right)$; filtrado em millipore $(0,22 \mathrm{~mm}$ de diâmetro) e a fração retida no filtro millipore após a filtragem do produto, e dois modos de aplicação (foliar e no substrato) e, como testemunhas oxitetraciclina + sulfato de estreptomicina $\left(0,8 \mathrm{~g} \mathrm{~L}^{-1}\right)$, oxicloreto de cobre $\left(2,4 \mathrm{~g} \mathrm{~L}^{-1}\right)$ e água. O Agrobio original e filtrado em aplicação foliar, em geral, proporcionaram melhor controle da doença e maior desenvolvimento das mudas que o Agrobio autoclavado ou a sua fração retida em aplicação via substrato. $\mathrm{O}$ controle da doença pelo Agrobio, foi inferior ao proporcionado pelos produtos comerciais à base de oxicloreto de cobre e de oxitetraciclina + sulfato de estreptomicina, porém foi estatisticamente superior à testemunha água. O Agrobio favoreceu, porém, o desenvolvimento vegetativo das mudas, o aumento da área foliar, a maior retenção das folhas infectadas e a população de Bacillus spp.
\end{abstract}

Palavras-chave: Capsicum annuum, Xanthomonas axonopodis pv. vesicatoria, antibiose, epidemiologia, controle.

\begin{abstract}
Effect of the Agrobio biofertilizer on the bacterial spot and the development of bell pepper transplants

The Agrobio biofertilizer is prepared from fresh cattle manure, water, molasses and minerals in open containers. This product has been widely used by organic and conventional farmers of the Rio de Janeiro State to control several plant pathogens. This research aimed to elucidate and quantify some of the aspects related to the beneficial effect of Agrobio on bell pepper (Capsicum annuum L.) transplants under greenhouse conditions. Two cultivars, 'Cascadura Ikeda' and 'Cascadura Itaipu' were used. Four Agrobio treatments, all diluted $5 \%(\mathrm{v} / \mathrm{v})$ in distilled water were used. They consisted of: (a) raw; (b) autoclaved $\left(120^{\circ} \mathrm{C} / 20 \mathrm{~min}\right)$; (c) filtered in millipore $(0,22 \mu$ diameter $)$ and (d) the fraction retained on the millipore. They were applied as foliage sprays or directly on the substrate. As control treatments, oxytetracicline + streptomycin sulphate $\left(0.8 \mathrm{~g} \mathrm{~L}^{-1}\right)$, copper oxichloride $\left(2.4 \mathrm{~g} \mathrm{~L}^{-1}\right)$ and water were used. Raw of filtered Agrobio, as a foliage spray, resulted in better control of the disease and higher growth of the transplants, compared to autoclaved and fraction retained of the Agrobio and substrate sprays. All Agrobio treatments resulted in a less satisfactory disease control when compared to the commercial products, copper oxichloride and oxitetracicline + streptomycin sulphate, but more, effective than water. Agrobio stimulated the vegetative growth of the transplants, reduced the incidence of bacterial spot, increased the leaf area and promoted a better retention of infected leaves and the Bacillus spp. population.
\end{abstract}

Keywords: Xanthomonas axonopodis pv. vesicatoria, Capsicum annuи L., antibiosis, epidemiology, control.

\section{(Recebido para publicação em 25 de novembro de 2003 e aceito em 29 de novembro de 2004)}

$\mathrm{C}_{8}$ om a expansão da agricultura orgânica e a recente normatização desse sistema de produção (Ministério da Agricultura, 1999 e 2001) muitos produtos alternativos têm sido lançados e testados por produtores orgânicos e convencionais em fase de transição. Uma das alternativas disponíveis para o manejo de pragas e de doenças são os biofertilizantes, usados por agricultores do Rio de Janeiro, Paraná, Rio Grande do Sul, São Paulo e Espírito Santo (Bettiol et al., 1997). No estado do Rio de Janeiro, um dos biofertilizantes mais conhecidos e utilizados em várias culturas é o Agrobio (Fernandes, 2000), produzido e pesquisado na Estação Experimental de Seropédica da PESAGRO- RIO.

Este produto é usado como fertilizante foliar e também para controlar algumas doenças em mudas de hortaliças folhosas, ornamentais e fruteiras em geral. Aos biofertilizantes são atribuídas propriedades como o aumento da resistência natural das plantas ao ataque de fitopatógenos e de algumas pragas (Vairo dos Santos, 1991; Bettiol et al., 1997).
O Agrobio é obtido por meio da transformação microbiana, em sistema aberto, de uma mistura de água, esterco bovino fresco, melaço, leite e sais minerais. Após cerca de 56 dias, dependendo das condições ambientais, estabiliza-se e pode ser engarrafado para uso em lavouras (Fernandes, 2000).

Os biofertilizantes em geral, ao serem aplicados nas culturas, atuam como fonte suplementar de micronutrientes para as plantas e a sua ação pode também contribuir para o aumento da resistência natural das plantas ao ataque de

${ }^{1}$ Parte da Dissertação de Mestrado apresentada pela primeira autora ao Curso de Pós-Graduação em Fitotecnia da UFRRJ; bolsista da CAPES. 
pragas e de patógenos, além de exercerem ação direta sobre os fitoparasitas, devido à presença de substâncias tóxicas na calda (Pinheiro e Barreto, 1996; Nunes e Leal, 2001).

No Agrobio, assim como nos biofertilizantes em geral, há uma comunidade microbiana composta por fungos unicelulares e filamentosos e bactérias, incluindo Bacillus subtilis. Sua ação pode ser, ainda, resultado da presença de antibióticos e da intensa atividade microbiana propiciada pelas aplicações freqüentes do produto (Tratch e Bettiol, 1997; Deleito, 2002).

Apesar dos muitos benefícios creditados ao Agrobio, existem poucos relatos quantificando ou explicando seus efeitos. No cultivo protegido do tomateiro sob manejo orgânico, conduzido na EES/PESAGRO-RIO, observou-se que pragas e doenças foram mantidas sob controle mediante o uso do produto, da calda sulfocálcica e de adubação orgânica, sendo a produção final equivalente à obtida com o uso de insumos químicos (Fernandes et al., 2000). Pulverizações com o biofertilizante em mudas de maracujazeiro amarelo (Passiflora edulis f. flavicarpa L.) proporcionaram maior altura, diâmetro, número de ramos, número de flores, de frutos e deixaram a cultura livre de doenças fúngicas e bacterianas (Collard et al., 2000).

Tendo em vista a necessidade de se desenvolverem tecnologias adequadas ao manejo agroecológico de hortaliças e de se conhecer a eficiência e o modo de ação do Agrobio, no presente trabalho avaliou-se a eficiência deste biofertilizante no controle da manchabacteriana, causada por Xanthomonas axonopodis pv. vesicatoria (Jones et al., 1998) e seus efeitos sobre o desenvolvimento das mudas de pimentão, em condições de casa-de-vegetação.

\section{MATERIAL E MÉTODOS}

Para elucidar o efeito do produto sobre mudas de pimentão e sobre o controle da mancha bacteriana, foram realizados dois ensaios simultâneos em condições de casa-de-vegetação, com duas cultivares, Cascadura Ikeda e Cascadura Itaipu. Os ensaios foram realizados na UFRRJ, de setembro a outu- bro de 2001. As sementes foram semeadas em setembro de 2001 em bandejas de polipropileno com substrato comercial. Como fonte de inóculo primário, para cada parcela, utilizaram-se três mudas de pimentão, previamente inoculadas, por atomização, com o isolado ENA 818 de $X$. axonopodis pv. vesicatoria, transplantadas aos 14 dias após a semeadura, quando se iniciou a aplicação dos tratamentos. Em cada um dos dois ensaios, compararam-se quatro apresentações do Agrobio $(\mathrm{pH}$ 5,5 e cerca de $34,7 \mathrm{~g} \mathrm{~L}^{-1}$ de matéria orgânica, $631 \mathrm{mg} \mathrm{L}^{-1}$ de nitrogênio, $170 \mathrm{mg} \mathrm{L}^{-1}$ de fósforo, $1200 \mathrm{mg} \mathrm{L}^{-1}$ de potássio, 159 $\mathrm{mg} \mathrm{L}^{-1}$ de cálcio e $480 \mathrm{mg} \mathrm{L}^{-1} \mathrm{de}$ magnésio, além de traços de micronutrientes) e duas formas diferentes de aplicação (via foliar e via solo/ substrato), além de três tratamentos controle, em esquema fatorial com três tratamentos adicionais $(4 \times 2+3)$. O Agrobio, diluído a 5\% em água destilada, foi previamente submetido aos seguintes preparos: Agrobio original passado em filtro de papel (Trat. 1) para retirar as partículas mais grosseiras que poderiam obstruir o bico do pulverizador; Agrobio autoclavado $\left(120^{\circ} \mathrm{C} / 20\right.$ minutos) e passado em papel de filtro (Trat. 2); Agrobio filtrado em millipore (0,22 mm de diâmetro) (Trat. 3 ) e a fração retida no filtro millipore após a filtragem do produto (Trat. 4). Foram realizadas quatro aplicações sendo que os tratamentos aplicados na parte aérea das mudas foram feitos com um pulverizador para cada tratamento e a aplicação via substrato foi feita pela imersão das bandejas na calda até absorção completa do líquido. Como tratamentos adicionais compararam-se: oxitetraciclina + sulfato de estreptomicina $\left(0,8\right.$ g. $\left.\mathrm{L}^{-1}\right)$, oxicloreto de cobre $\left(2,4\right.$ g. $\left.\mathrm{L}^{-1}\right)$, seguindo recomendação dos fabricantes, e água, também pulverizados semanalmente em um total de quatro aplicações. Adotou-se o delineamento inteiramente casualizado com três repetições. Cada parcela foi composta por 64 mudas.

As avaliações foram efetuadas ao final do ensaio, quando as mudas atingiram o ponto de transplante, cerca de seis semanas após a semeadura. Inicialmente, contou-se o número total de mudas por parcela e o número de mu- das com sintomas de mancha-bacteriana. Após essa primeira contagem, foram coletadas 20 mudas por parcela e submetidas às seguintes avaliações: peso da matéria seca e altura da parte aérea e comprimento e peso da matéria seca das raízes. Para o ensaio com a cultivar Cascadura Itaipu, tomaram-se cinco plantas de cada parcela das quais foram contados o número de folhas e de folhas caídas e medidas as áreas foliares. Outro grupo de 15 plantas, sendo cinco de cada parcela, foram secas e moídas para determinação dos teores de macro e micronutrientes nas folhas e nas raízes (Silva, 1999).

Os dados obtidos em cada um dos ensaios foram analisados separadamente pelo teste $\mathrm{F}$ e teste de Tukey a 5\% para comparação das médias. Os dados relativos ao ensaio com a cv. Cascadura Itaipu foram ainda submetidos à análise de Correlação de Pearson. Adotaram-se como significativos os valores de $r>+0,60$ ou $<-0,60$ e significância de até $1 \%$.

Paralelamente a essas avaliações, foi feita a quantificação da população microbiana residente no filoplano a partir de amostras de nove folhas assintomáticas, coletadas na porção mediana de três plantas de cada parcela do ensaio com a cultivar Cascadura Itaipu conforme Aguiar et al. (2003). Destas folhas foram retirados 18 discos foliares de 1,3 $\mathrm{cm}^{2}$ (dois discos/folha), com auxílio de furador-de-rolha. Imediatamente após, os discos foram colocados em frascos de Erlenmeyer de 250 $\mathrm{ml}$, contendo $20 \mathrm{ml}$ de solução extratora esterilizada (5,3 g de $\mathrm{KH}_{2} \mathrm{PO}_{4}, 8,6 \mathrm{~g}$ de $\mathrm{Na}_{2} \mathrm{HPO}_{4}$ e $1,0 \mathrm{~g}$ de peptona bacteriológica $\mathrm{L}^{-1}$ de água, ajustada para $\mathrm{pH} 7,0)$. Os frascos, correspondentes a cada parcela, foram então agitados por 30 minutos em agitador regulado para 150 oscilações por minuto. Após esse período de agitação, alíquotas de $0,5 \mathrm{ml}$ foram pipetadas e submetidas a quatro diluições, série 1:10, em tampão fosfato a $0,005 \mathrm{M}(\mathrm{pH} 7,0)$, contendo $0,85 \%$ de $\mathrm{NaCl}$. Dessas diluições, novas alíquotas de $0,1 \mathrm{ml}$ foram distribuídas uniformemente na superfície de três placas de Petri contendo os meios Nutriente Ágar (Fahy e Hayward, 1983) para quantificação de Xanthomonas axonopodis pv. vesicatoria e BDA para 
Tabela 1. Interação entre diferentes apresentações do biofertilizante Agrobio e o local de aplicação (foliar ou no substrato), de três tratamentos adicionais e comparação entre tratamentos com Agrobio e adicionais sobre o comprimento da haste $(\mathrm{cm})$ e da raiz $(\mathrm{cm})$, peso da matéria seca da parte aérea e da raiz (g), incidência de mudas com sintomas da mancha-bacteriana (\%) e área foliar ( $\left.\mathrm{cm}^{2}\right)$ em mudas de pimentão, cv. Cascadura Itaipu. Seropédica (RJ), UFRRJ, 2001.

\begin{tabular}{|c|c|c|c|c|c|c|c|c|c|c|c|}
\hline \multirow{3}{*}{$\begin{array}{l}\text { Tratamentos } \\
\text { Agrobio } x \text { local de } \\
\text { aplicação }{ }^{1}\end{array}$} & \multicolumn{4}{|c|}{ Comprimento (cm) } & \multicolumn{3}{|c|}{ Peso da matéria seca $(\mathrm{g})$} & \multirow{2}{*}{\multicolumn{2}{|c|}{$\begin{array}{c}\text { Incidência de } \\
\text { mancha } \\
\text { bacteriana (\%) }\end{array}$}} & \multirow{2}{*}{\multicolumn{2}{|c|}{ Área Foliar $\left(\mathrm{cm}^{2}\right)$}} \\
\hline & \multicolumn{2}{|c|}{ Haste } & \multicolumn{2}{|c|}{ Raíz } & \multicolumn{2}{|c|}{ Parte aérea } & \multirow[t]{2}{*}{ Raíz } & & & & \\
\hline & Foliar & Substrato & Foliar & Substrato & Foliar & Substrato & & Foliar & Substrato & Foliar & Substrato \\
\hline Agrobio original & $17,7 \mathrm{Aa}$ & $13,8 \mathrm{Ba}$ & $10,7 \mathrm{Aa}$ & $9,6 \mathrm{Bb}$ & $0,74 \mathrm{Aa}$ & 0,61 Ba & $0,35 a$ & $37,5 \mathrm{Bd}$ & $56,1 \mathrm{Ad}$ & $14,9 \mathrm{Aa}$ & $12,4 \mathrm{Ba}$ \\
\hline $\begin{array}{l}\text { Agrobio autoclavado } \\
\left(120^{\circ} \mathrm{C}\right)\end{array}$ & $13,6 \mathrm{Ab}$ & $13,6 \mathrm{~A} \mathrm{a}$ & $9,6 \mathrm{~A} \mathrm{~b}$ & $9,6 \mathrm{Ab}$ & $0,55 \mathrm{Ab}$ & $0,52 \mathrm{Aab}$ & $0,30 \mathrm{a}$ & $53,6 \mathrm{Bb}$ & $72,5 \mathrm{Ac}$ & $11,9 \mathrm{Ac}$ & $11,5 \mathrm{Bb}$ \\
\hline $\begin{array}{l}\text { Agrobio filtrado }(0,22 \\
\mu \mathrm{m})\end{array}$ & $17,6 \mathrm{Aa}$ & $14,1 \mathrm{Ba}$ & $10,8 \mathrm{Aa}$ & $10,7 \mathrm{Aa}$ & 0,72Aab & 0,57 Ba & $0,34 \mathrm{a}$ & $41,9 \mathrm{Bc}$ & $74,8 \mathrm{Ab}$ & $13,8 \mathrm{Ab}$ & $11,6 \mathrm{Bb}$ \\
\hline $\begin{array}{l}\text { Agrobio retido no } \\
\text { filtro }\end{array}$ & $12,4 \mathrm{Ac}$ & $11,0 \mathrm{Bb}$ & $6,3 \mathrm{Bc}$ & $7,4 \mathrm{Ac}$ & $0,55 \mathrm{Ab}$ & $0,45 \mathrm{~B} \mathrm{~b}$ & $0,22 \mathrm{~b}$ & $61,5 \mathrm{Ba}$ & $89,9 \mathrm{Aa}$ & $10,4 \mathrm{Ad}$ & $9,7 \mathrm{Bc}$ \\
\hline \multicolumn{12}{|l|}{$\begin{array}{l}\text { Tratamentos } \\
\text { Adicionais }^{2}\end{array}$} \\
\hline $\begin{array}{l}\text { Oxitetraciclina+ Estre- } \\
\text { ptomicina }\end{array}$ & \multicolumn{2}{|c|}{11,8 a } & \multicolumn{2}{|c|}{$5,1 a b$} & \multicolumn{2}{|c|}{$0,52 \mathrm{a}$} & $0,14 a$ & \multicolumn{2}{|c|}{$3,1 \quad \mathrm{c}$} & \multicolumn{2}{|c|}{9,9 a } \\
\hline Oxicloreto de cobre & \multicolumn{2}{|c|}{$10,6 \mathrm{~b}$} & \multicolumn{2}{|c|}{5,6 a } & \multicolumn{2}{|c|}{0,47 a } & $0,19 a$ & \multicolumn{2}{|c|}{7,2 b } & \multicolumn{2}{|c|}{$9,6 \mathrm{a}$} \\
\hline Água & \multicolumn{2}{|c|}{$7,7 \quad \mathrm{c}$} & \multicolumn{2}{|c|}{$4,5 \mathrm{~b}$} & \multicolumn{2}{|c|}{$0,34 \mathrm{~b}$} & $0,16 \mathrm{a}$ & \multicolumn{2}{|c|}{$100,0 \mathrm{a}$} & \multicolumn{2}{|c|}{$9,5 \mathrm{~b}$} \\
\hline \multicolumn{12}{|l|}{ Média dos Grupos ${ }^{2}$} \\
\hline $\begin{array}{l}\text { Tratamentos com } \\
\text { Agrobio }\end{array}$ & \multicolumn{2}{|c|}{$14,2 \mathrm{a}$} & \multicolumn{2}{|c|}{9,3 a } & \multicolumn{2}{|c|}{$0,60 \mathrm{a}$} & $0,31 \mathrm{a}$ & \multicolumn{2}{|c|}{61,00 a } & \multicolumn{2}{|c|}{$12,0 \mathrm{a}$} \\
\hline $\begin{array}{l}\text { Tratamentos } \\
\text { Adicionais } \\
\end{array}$ & \multicolumn{2}{|c|}{$9,9 \mathrm{~b}$} & \multicolumn{2}{|c|}{$5,0 \quad b$} & \multicolumn{2}{|c|}{$0,44 \quad b$} & $0,16 \mathrm{~b}$ & \multicolumn{2}{|c|}{$36,78 \quad b$} & \multicolumn{2}{|c|}{$8,6 \mathrm{~b}$} \\
\hline CV \% & & 21 & & 3,57 & & 9,08 & 11,11 & & 0,63 & & 40 \\
\hline
\end{tabular}

${ }^{1}$ Médias seguidas pela mesma letra maiúscula na linha e minúscula na coluna não diferem estatisticamente pelo teste de Tukey a $5 \%$.

${ }^{2}$ Médias seguidas pela mesma letra minúscula na coluna não diferem estatisticamente pelo teste $\mathrm{F}$ a $5 \%$.

Bacillus sp. Para isolamento de Bacillus as amostras foram inicialmente expostas em banho-Maria por 20 minutos a $80^{\circ} \mathrm{C}$ (Bettiol, 1995). Após 36 horas de incubação a $27+2^{\circ} \mathrm{C}$, foram feitas as contagens do número de colônias típicas de $X$. axonopodis pv. vesicatoria e de Bacillus sp., confirmadas por meio de observações em microscópio estereoscópico e óptico. Os resultados obtidos nas contagens foram expressos em número de unidades formadoras de colônias por $\mathrm{cm}^{2}$ de limbo foliar (ufc $\mathrm{cm}^{-2}$ ).

\section{RESULTADOS E DISCUSSÃO}

Nos ensaios com as duas cultivares observou-se efeito significativo da preparação do Agrobio e do local de aplicação, diferença significativa entre os tratamentos adicionais, e entre os tratamentos à base de Agrobio e os adicionais sobre as variáveis avaliadas.

$\mathrm{Na}$ cultivar Cascadura Itaipu observou-se que a aplicação foliar comparada à aplicação via substrato, proporcionou, para a maioria dos tratamentos, maior comprimento das hastes e das raízes, maior peso da matéria seca da parte aérea, maior área foliar e menor incidência de mudas com sintomas de mancha-bacteriana (Tabela 1). Entre as quatro apresentações do biofertilizante, o produto original (Trat. 1) e filtrado em millipore (Trat. 3), seguido do autoclavado (Trat. 2), principalmente quando aplicados via foliar, proporcionaram em geral maior desenvolvimento das mudas, expresso pelo maior comprimento das hastes e das raízes, maior peso da matéria seca da parte aérea e das raízes e maior área foliar, além de maior controle da mancha-bacteriana, expresso pela redução da incidência da doença (Tabela 1) e pela redução da taxa de mortalidade das mudas, $0,0 \%$ no produto original (Trat. 1) e no filtrado em millipore (Trat. 3 ) e $0,53 \%$ e 2,2 no produto autoclavado (Trat. 2) e na fração retida no filtro millipore (Trat. 4), respectivamente. A redução da incidência da doença nas aplicações foliares, comparada à aplicação via substrato, confirma a ação bacteriostática do Agrobio relatada por Deleito (2002). A fração do biofertilizante retida no filtro millipore (Trat. 4), independente do local de aplicação, apresentou sempre médias de comprimento e peso da parte aérea e da raiz estatisticamente inferiores às dos demais tratamentos (Tabela 1), provavelmente por conter a fração não decomposta da matéria orgânica e menor concentração de nutrientes.

Entre os tratamentos adicionais, observou-se maior comprimento das hastes e peso da matéria seca da parte aérea nos tratamentos com oxicloreto de cobre e com oxitetraciclina + sulfato de estreptomicina comparado à água, maior comprimento das raízes no tratamento com oxicloreto de cobre em relação à água que por sua vez não diferiram do tratamento com oxitetraciclina + sulfato de estreptomicina e nenhuma diferença entre os três tratamentos quanto ao peso da matéria seca das raízes (Tabela 1). Quanto à comparação entre os tratamentos à base de biofertilizante com os três tratamentos adicionais, observou-se sempre diferenças significativas entre os mesmos, com maiores médias de comprimento das hastes e das raízes, de peso 
Tabela 2. Interação entre diferentes apresentações do biofertilizante Agrobio e o local de aplicação, foliar ou no substrato, de três tratamentos adicionais e comparação entre tratamentos com Agrobio e adicionais sobre o comprimento da haste $(\mathrm{cm})$, o peso da matéria seca da parte aérea e das raízes (g) e a incidência de mudas com sintomas da mancha-bacteriana (\%) em mudas de pimentão, cv. Cascadura Ikeda. Seropédica-RJ, UFRRJ, 2001.

\begin{tabular}{|c|c|c|c|c|c|c|}
\hline \multirow{2}{*}{$\frac{\text { Tratamentos }}{\text { Agrobio }^{x} \text { local de aplicação }}$} & \multicolumn{2}{|c|}{ Comprimento da haste $(\mathrm{cm})$} & \multicolumn{2}{|c|}{ Peso da matéria seca ( $\mathrm{g}$ ) } & \multicolumn{2}{|c|}{$\begin{array}{c}\text { Incidência de mancha } \\
\text { bacteriana (\%) }\end{array}$} \\
\hline & Foliar & Substrato & Parte aérea & Raíz & Foliar & Substrato \\
\hline Agrobio original & $17,4 \mathrm{Aa}$ & $13,8 \mathrm{Ba}$ & $0,65 \mathrm{a}$ & $0,31 \mathrm{a}$ & $6,8 \mathrm{Bc}$ & $7,3 \mathrm{Ab}$ \\
\hline Agrobio autoclavado $\left(120^{\circ} \mathrm{C}\right)$ & $13,6 \mathrm{Ab}$ & $13,8 \mathrm{Aa}$ & $0,54 \mathrm{~b}$ & $0,30 a b$ & $7,8 \mathrm{Ab}$ & $6,8 \mathrm{Bb}$ \\
\hline Agrobio filtrado $(20 \mu \mathrm{m})$ & $17,8 \mathrm{Aa}$ & $14,4 \mathrm{Ba}$ & $0,63 a$ & $0,34 \mathrm{a}$ & $6,8 \mathrm{Ac}$ & $6,8 \mathrm{Ab}$ \\
\hline Agrobio retido no filtro & $12,4 \mathrm{Ac}$ & $11,4 \mathrm{Bb}$ & $0,51 \mathrm{~b}$ & $0,23 \mathrm{~b}$ & $8,8 \mathrm{Aa}$ & $8,6 \mathrm{Aa}$ \\
\hline \multicolumn{7}{|l|}{ Tratamentos Adicionais $^{2}$} \\
\hline Oxitetraciclina + estreptomicina & \multicolumn{2}{|c|}{$12,6 \mathrm{a}$} & \multicolumn{2}{|r|}{$0,15 a$} & \multicolumn{2}{|c|}{$0,0 \mathrm{c}$} \\
\hline Oxicloreto de cobre & \multicolumn{2}{|c|}{$10,0 \mathrm{~b}$} & $0,34 \mathrm{~b}$ & $0,17 \mathrm{a}$ & \multicolumn{2}{|c|}{$0,3 \mathrm{~b}$} \\
\hline Água & \multicolumn{2}{|c|}{$7,6 \mathrm{c}$} & $0,46 \mathrm{a}$ & $0,14 \mathrm{a}$ & \multicolumn{2}{|c|}{$20,0 \mathrm{a}$} \\
\hline \multicolumn{7}{|l|}{ Média dos Grupos $^{2}$} \\
\hline Tratamentos com Agrobio & \multicolumn{2}{|c|}{$14,3 \mathrm{a}$} & $0,58 \mathrm{a}$ & $0,29 a$ & \multicolumn{2}{|c|}{7,4 a } \\
\hline Tratamentos Adicionais & \multicolumn{2}{|c|}{$10,4 \quad b$} & $0,44 \quad b$ & \multirow{2}{*}{$\begin{array}{l}0,15 \quad \text { b } \\
18,89\end{array}$} & \multicolumn{2}{|c|}{$6,9 \mathrm{~b}$} \\
\hline CV \% & \multicolumn{2}{|c|}{2,21} & 9,46 & & \multicolumn{2}{|c|}{3,57} \\
\hline
\end{tabular}

${ }^{1}$ Médias seguidas pela mesma letra maiúscula na linha e minúscula na coluna não diferem estatisticamente pelo teste de Tukey a $5 \%$.

${ }^{2}$ Médias seguidas pela mesma letra minúscula na coluna não diferem estatisticamente pelo teste $\mathrm{F}$ a $5 \%$.

da matéria seca da parte aérea e das raízes e maior área foliar nas parcelas que receberam o biofertilizante, comparada aos tratamentos adicionais, porém, significativamente maior incidência da mancha bacteriana nos tratamentos com o biofertilizante comparado aos adicionais (Tabela 1), apesar de menor taxa de mortalidade das mudas no primeiro, $0,67 \%$, e $1,52 \%$ nos tratamentos adicionais.

$\mathrm{O}$ maior desenvolvimento das mudas tratadas com Agrobio comparadas àquelas onde foram aplicados os tratamentos adicionais concordam com os resultados de Collard et al. (2000) que também verificaram maior desenvolvimento vegetativo de mudas de maracujazeiro pulverizadas com o Agrobio e com os de Nunes e Leal (2001) que observaram maior vigor de plantas de tomateiro pulverizadas com biofertilizante comparado a vários outros tratamentos. Acredita-se que este efeito possa estar associado ao acréscimo de macro e micronutrientes presentes no biofertilizante Agrobio (Fernandes, 2000), precisando, porém, esta hipótese ser melhor investigada. No presente trabalho, efetuou-se a análise foliar e, apesar desta ter indicado teores de macronutrientes, em todos os tratamentos, dentro da faixa ideal para plantas de pimentão (Silva, 1999) a mesma não é conclusiva pois, foi feita a partir de uma amostra composta de plantas coletadas nas três repetições, o que impediu a análise estatística e comparação do efeito nutricional dos tratamentos. Deve ser ressaltado, porém, a elevação dos teores de cobre $\left(2700 \mathrm{mg} \mathrm{kg}^{-1}\right)$ e de boro (320 mg kg $\mathrm{mg}^{-1}$ ) nas parcelas pulverizadas com oxicloreto e cobre e Agrobio, respectivamente, $100 \mathrm{x}$ e $2 \mathrm{x}$ maior que os valores registrado nas parcelas que não receberam estes dois respectivos tratamentos.

Para 'Cascadura Ikeda', em geral, a aplicação foliar do Agrobio resultou em maior altura das mudas, expressa pelo comprimento das hastes (Tabela 2) porém, nenhuma diferença clara sobre o controle da doença, presente em baixa incidência, 6,8 a $8,8 \%$, comparada à 'Cascadura Itaipu', 37,5 a 89,9 (Tabelas 1 e 2). Entre as quatro apresentações do biofertilizante, no entanto, o produto original (Trat. 1) ou filtrado em millipore (Trat. 3), a exemplo do observado com a cultivar Cascadura Itaipu (Tabela 1), proporcionou maior desenvolvimento das mudas, expresso pelo maior comprimento das hastes e maior peso da matéria seca da parte aérea e das raízes comparado à fração do biofertilizante retida no filtro millipore (Trat. 4) (Tabela 2). Observou-se, ainda, diferença significativa entre as apresentações do biofertilizante sobre o con- trole da doença, expressa pela significativamente menor incidência da doença nas parcelas tratadas com o produto original e filtrado seguido de autoclavado, comparado à fração retida no filtro (Tabela 2), confirmando as observações de Deleito (2002) em testes de antibiose in vitro. Entre os tratamentos adicionais, observaram-se resultados semelhantes aos encontrados para 'Cascadura Itaipu' para o comprimento da haste, e peso da matéria seca da raiz (Tabelas 1 e 2). O efeito dos tratamentos sobre o peso da matéria seca da parte aérea, no entanto, diferiu daquele observado para 'Casacadura Itaipu' (Tabelas 1 e 2). Em 'Cascadura Ikeda', registraram-se maiores pesos no tratamento com antibiótico e água em relação ao oxicloreto de cobre (Tabela 2). Esta redução do crescimento das mudas pela aplicação de oxicloreto de cobre está de acordo com os resultados de Aguiar (1997) que relata efeito fitotóxico, incluindo redução do crescimento das plantas de pimentão, a partir da dose de $28 \mathrm{mg} \mathrm{L}^{-1}$ de cobre, em aplicações semanais. Este comportamento distinto das duas cultivares, provavelmente, deve-se à diferença entre estas quanto à suscetibilidade à mancha-bacteriana (Carmo et al., 1998) expressa pelo maior desenvolvimento da doença em 'Cascadura Itaipu' que em 'Cascadura 
Ikeda', 36,7\% e 6,9\% de incidência média nos tratamentos adicionais, respectivamente, e ao efeito do cobre no controle da doença. Ao se comparar os dois grupos de tratamentos, semelhante ao observado com 'Cascadura Itaipu', observou-se maior peso da matéria seca da parte aérea das raízes e maior altura das hastes e maior incidência da doença nos tratamentos com o biofertilizante comparado aos adicionais (Tabelas 1 e 2).

A média geral de incidência da doença dos tratamentos à base de biofertilizante foi maior que a média dos três tratamentos adicionais, principalmente na cultivar mais suscetível, 'Cascadura Itaipu', porém foi inferior à registrada na testemunha água (Tabelas 1 e 2). A maior intensidade da doença na testemunha água resultou em menor desenvolvimento das mudas, principalmente na cultivar mais suscetível Cascadura Itaipu (Tabela 1), onde se observou intensa desfolha. O tratamento água apresentou ao final do ensaio $100 \%$ e $20 \%$ de mudas infectadas nas cultivares Cascadura Itaipu e Cascadura Ikeda, respectivamente, enquanto que os tratamentos biofertilizante original e filtrado aplicados via foliar apresentaram incidência de 37 e $41 \%$, respectivamente para Cascadura Itaipu e 6,8 e 6,8\% para Cascadura Ikeda. Estes resultados concordam com os de Deleito (2002) que relata ação bacteriostática do Agrobio in vitro, porém com ação significativamente menor que a do cobre e do sulfato de estreptomicina.

O Agrobio, apesar de menos eficiente em reduzir as infecções pelo patógeno, permitiu uma maior retenção das folhas infectadas, visível pela significativamente maior área foliar nas parcelas tratadas com o Agrobio comparadas aos tratamentos adicionais (Tabela 1), o que provavelmente contribuiu para o maior desenvolvimento das mudas. O aumento da área foliar deve-se tanto à redução das infecções devido à sua ação bacteriostática (Deleito, 2002), quanto à redução da taxa de desfolha. Esta doença caracteriza-se por promover a abscisão prematura de folhas infectadas (Carmo et al., 2001), reduzindo a área foliar das plantas. Isto pode ser confirmado pela análise de correlação efetuada para os dados coletados no ensaio com 'Cascadura Itaipu' onde se constatou correlação negativa e significativa entre a incidência da doença com a altura das plantas $(\mathrm{r}=-0,87)$, com o peso da matéria seca da parte aérea $(\mathrm{r}=$ $0,80)$ e com a área foliar $(\mathrm{r}=-0,87)$.

Os isolamentos feitos a partir das folhas das mudas de 'Cascadura Itaipu' revelaram maior diversidade microbiana nas parcelas pulverizadas com o Agrobio e redução a quase zero da flora nas parcelas pulverizadas com cobre e antibiótico. Quantitativamente, no entanto, só foi avaliada a população de $X$. axonopodis pv. vesicatoria e de Bacillus sp. A população da fitobactéria foi maior nas mudas pulverizadas com água (75 ufc $\mathrm{cm}^{-2}$ ) e $50 \%$ menor nas parcelas pulverizadas com Agrobio (37 ufc. $\mathrm{cm}^{-2}$ ), seguido dos tratamentos cobre (14 ufc $\mathrm{cm}^{-2}$ ) e antibiótico (4 ufc $\mathrm{cm}^{-2}$ ). Quanto à população de Bacillus sp., esta foi maior no tratamento Agrobio (13 ufc $\mathrm{cm}^{-2}$ ), seguido de água (6 ufc $\mathrm{cm}^{-2}$ ) e cobre (4 ufc $\mathrm{cm}^{-2}$ ) e ausente no tratamento com antibiótico. Estes resultados concordam com os de Deleito (2002) que isolou Bacillus de $100 \%$ das amostras de Agrobio testadas, independente de sua idade e, com a afirmação de Bettiol et al. (1997) de que a ação dos biofertilizantes no controle de doenças se deve a um conjunto de efeitos, desde nutricionais, presença de substâncias com ação antimicrobiana e aumento da atividade da flora benéfica no filoplano. Deve-se considerar, no entanto, a baixa precisão do presente ensaio na quantificação da flora microbiana devido às prováveis interferências entre as parcelas.

Finalmente, pode-se afirmar que o Agrobio apresentou efeito benéfico ao desenvolvimento das mudas de pimentão e redução da incidência da mancha bacteriana, porém inferior aos bactericidas comerciais. O melhor desenvolvimento das plantas e a redução das infecções pela fitobactéria são resultado de uma interação complexa envolvendo, provavelmente, um conjunto de fatores, podendo-se incluir entre estes a ação antibiótica dos metabólitos produzidos pelos microrganismos durante o seu processo de fabricação, competição microbiana no filoplano e efeitos nutricionais discretos ou pro- motores de crescimento, constatado principalmente pela maior retenção das folhas infectadas, expressa pelos maiores valores de área foliar nos tratamentos com Agrobio, comparado aos adicionais.

\section{AGRADECIMENTOS}

À CAPES pela concessão da bolsa de Mestrado à primeira autora, ao $\mathrm{CNPq}$ e à FAPERJ pelo financiamento do projeto.

\section{LITERATURA CITADA}

AGUIAR, L.A. Identificação de isolados nacionais de Xanthomonas campestris pv. vesicatoria, agente da mancha-bacteriana do pimentão (Capsicum annuum L.), resistentes ao cobre e perspectivas de seu controle com formulações cúpricas e cuprorgânicas. 1997. 153 f. (Tese mestrado) - UFRRJ; Seropédica.

AGUIAR, L.A.; KIMURA, O.; CASTILHO, A.M.C.; CASTILHO, K.S.C.; RIBEIRO, R.L.D.; AKIBA, F.; CARMO, M.G.F. Efeito de formulações cúpricas e cuprorgânicas na severidade da mancha-bacteriana e na população residente de Xanthomonas campestris pv. vesicatoria em pimentão. Horticultura Brasileira, Brasília, v.21, n.1, p.44-50, 2003.

BETTIOL, W. Isolamento seletivo de Bacillus. In: MELO, I.S.; SANHUEZA, R.M.V. (Ed.). Métodos de seleção de microrganismos antagônicos a fitopatógenos - Manual Técnico. Jaguariúna: EMBRAPA - CNPMA, 1995. p.72.

BETTIOL, W.; TRATCH, R.; GALVÃO, J.A.H. Controle de doenças de plantas com biofertilizantes. Jaguariúna: EMBRAPA-CNPMA, 1997. 22 p. (EMBRAPA-CNPMA. Circular Técnica, 02)

CARMO, M.G.F.; SILVA, F.F.; CARVALHO, A.O.; SOUZA, E.P. Seleção de variedades de pimentão indicadoras da presença de Xanthomonas campestris pv. vesicatoria. In: Anais da VII Jornada de Iniciação Científica. Seropédica: UFRRJ, 1998. p.122-123.

CARMO, M.G.F.; MACAGNAN, D.; CARVALHO, A.O. Progresso da mancha-bacteriana do pimentão a partir de diferentes níveis iniciais de infecção e do emprego ou não do controle com oxicloreto de cobre. Horticultura Brasileira, Brasília, v.19, n.3, p.342-347, 2001.

COLlard, F.H.; AlmeIDA, A.; COSTA, M.D.R.; ROCHA, M.C. Efeito do uso do biofertilizante Agrobio na cultura do maracujazeiro amarelo (Passiflora edulis f. flovicarpa Deg). Revista Biociências, v.7, n.1, p.15-21, 2000.

DELEITO, C.S.R. O biofertilizante Agrobio: composição microbiana e efeito sobre a mancha bacteriana do pimentão. 2002. 95 f. (Tese mestrado) - UFRRJ, Seropédica.

FAHY, P.C.; HAYWARD, A.C. Media and methods for isolation and diagnostic test. In: FAHY, P.C. \& PERSLEY, G.J. (Ed.). Plant bacterial disease: a diagnostic guide. Sidney: Academic Press, 1983. Cap. 16, p. 337-338. 
FERNANDES, M.C.A. O biofertilizante Agrobio, A Lavoura, v.103, n.634, p.42-43, 2000.

FERNANDES, M.C.A.; LEAL, M.A.A.; RIBEIRO, R.L.D.; ARAÚJO, M.L.; ALMEIDA, D.L. Cultivo protegido do tomateiro sob manejo orgânico. A Lavoura, v.103, n.634, p.44-45, 2000.

JONES, J.B.; STALL, R.E.; BOUZAR, H Diversity among xanthomonads pathogenic on pepper and tomato. Annual Review of Phytopathology, v.36, p.41-58, 1998.

MINISTÉRIO DA AGRICULTURA E DO ABASTECIMENTO. Instrução Normativa $n^{0} 007$ de 17 de maio de 1999. Diário Oficial da União. p.9-11, 1999.
MINISTÉRIO DA AGRICULTURA E DO ABASTECIMENTO. Portaria $\mathrm{n}^{0} 17$ de 10 de abril de 2001. Diário Oficial da União. p.9-11, 2001.

NUNES, M.U.C.; LEAL, M.L.S. Efeitos de aplicação de biofertilizante e outros produtos químicos e biológicos no controle da broca pequena do fruto e na produção do tomateiro tutorado em duas épocas de cultivo e dois sistemas de irrigação. Horticultura Barsileira, Brasília, v.19, n,1, p.5359, 2001.

PINHEIRO, S.; BARRETO, S.B. MB-4 Agricultura sustentável, trofobiose e biofertilizantes. Blumenau: Cooperativa Ecológica Colméia, 1996. $280 \mathrm{p}$.
SILVA, F.C. Manual de análises químicas de solos, plantas e fertilizantes. Brasília: EMBRAPA, 1999.

TRATCH, R.; BETTIOL, W. Efeito de biofertilizantes sobre o crescimento micelial e a germinação de esporos de alguns fungos fitopatogênicos. Pesquisa Agropecuária Brasileira, Brasília, v.32, n.11, p.1131-1139, 1997.

VAIRO DOS SANTOS, A.C. Efeitos nutricionais e fitossanitários do biofertilizante orgânico líquido no campo. Fitopatologia Barasileira, Brasília, n.16, p.21-26, 1991. 